\title{
Communities and urban energy landscapes in Maputo, Mozambique
}

\author{
Vanesa Castán Broto*, Diana Salazar and Kevin Adams \\ Bartlett Development Planning Unit
}

\begin{abstract}
What is the role of energy in building communities and to what extent are communities invested in particular energy practices? The hypothesis of this paper is that energy is embedded in the everyday life of urban communities in multiple ways. The assemblage of shared understandings within the community and the material elements that mediate the provision of energy and its use constitute an urban energy landscape. While this energy landscape is embedded in wider political economies, communities also shape it both through discursive and material engagements with energy.

This hypothesis is examined with reference to an urban energy landscape in the neighbourhood Chamanculo $\mathrm{C}$, in Maputo, Mozambique. For this study, we conducted a participatory mapping workshop in which a representative group of local residents discussed the use of energy and mapped different elements of the energy system in their neighbourhood using walking as a research tool. The case study reveals multiple understandings of energy in the community and how energy is embedded in different forms of living and in livelihoods. The community shares a complex energy landscape in which multiple fuels and forms of energy co-exist. These findings question current energy policies for urban development focused exclusively on the extension of the electricity network and street lighting.
\end{abstract}

Keywords: Energy landscapes, urban communities, participatory mapping, Mozambique.

\section{Introduction}

In the city of Maputo how people interact with and use different energy sources depends on where they live. Most citizens do not live in the former colonial city, but rather, they live in sub-serviced neighbourhoods, the bairros, that extend towards the north across a rolling landscape with progressively deteriorating services or in the nearby city of Matola, at the back of the Maputo bay. Recent flooding events have shown the city's vulnerability to cyclones. Positive rates of growth and foreign 
investment have accelerated the development of the city and the construction of new infrastructures especially near the coast, but most bairros have only seen modest incremental improvements in infrastructure provision.

For people in these bairros, energy services are linked to urban health and livelihood opportunities. Access to electricity and public lighting have improved safety in the streets and opened up new possibilities to engage in economic activities. Most people in the bairros depend on charcoal for cooking and heating water, which represents an improvement on other fuels such as waste or firewood, but that still exposes households to accidents and indoor pollution. Access to mobile phones and internet mediate new forms of social and economic relationships and may be provoking a change in generational aspirations.

In Maputo, communities may be seen as related to the spatial division of the city into bairros and quarteirões, that have their own representatives and community organisations. For example, in one of these bairros, Chamanculo $C$, there are associations such as ASCODECHA, which works in adult education, or AMANDLA, which works in sustainable urban development. Over the years in Chamanculo $C$ people have mobilised to build community recreation spaces, improve drainage infrastructure, reduce vulnerability to flooding, organise the collection of waste, support orphans, and facilitate access to employment of local people. Moreover, as a community, their lives are embedded in social, economic and material exchanges across the neighbourhood that connect them with wider spaces. Local residents also work in relation to an institutional framework of formal organisation structures in groups of houses, with chefes and a bairro secretary, that define them as a community.

Alongside other relations around urban health and service provision, energy services mediate life in the community. The hypothesis of this paper is that energy is embedded in everyday life in communities in a set of changing socio-energetic relations that together form a distinctive urban energy landscape. Energy services are relevant both to improve quality of life and livelihoods. For urban communities such as the one in Chamanculo C, how energy matters to them and where energy services are lacking are related to the dynamics of the urban energy landscape.

In places like Chamanculo $\mathrm{C}$ communities play a key role in shaping energy provision through the daily practices of consumption of electricity and fuels, through the daily monitoring of neighbourhood furniture, from lamps to transmission towers, and through their role in the actual provision of fuels, such as charcoal. In a location like this, achieving universal provision relates to access to basic services such as lighting, cooking and enabling basic appliances (Grubler et al., 2012). Community energy does not relate to the provision of energy alone, but rather needs to focus on the question of siting and managing projects within a local context.

In the UK, questions of energy poverty and service provision tend to be framed in an individual manner, and therefore, the phrase 'community energy' evokes ideas about the mobilisation of communities to support and catalyse a transition to sustainable energy systems (e.g. Seyfang et al., 2010), as we see in the ever growing number of examples of community-managed energy projects. The idea of community may also be invoked in relation to mobilisation against big energy projects, for example, in relation to the siting of wind turbines (e.g. Cowell, Bristow and Munday, 2011) or more recently, against fracking. Alternatively, energy community relations can also be understood in relation to their significance in everyday life and how socio-energetic relations are embedded in cultures and places. In Maputo, where energy priorities focus on the delivery of centralised electricity infrastructure, current policies may be overlooking the complex ways in which energy matters in the everyday life of the communities. 
We take the concept of energy landscape as a point of entry to understand how energy uses and energy needs are constructed and lived within a community in a distinct geographical location in Chamanculo C, in Maputo. Looking at energy landscapes also provides insights into the heterogeneity of socio-energetic relations and their dynamics. To develop a bottom-up analysis of urban energy landscapes, we developed a participatory mapping methodology adapted to the context of Chamanculo C. The results section presents the findings of the participatory mapping exercise, highlighting the diversity of energy practices within the community and how they relate to the spatial aspects of community life, as well as to the rapid social and economic changes that are taking place in this community. Overall, the participatory mapping exercise demonstrated the local significance of energy and its use, showing that energy-society relations have an important role in mediating people's understandings of the self and the community in which they live.

\section{Urban energy landscapes}

In this paper, we approach the relationship between energy, community and place from a socio-technical perspective which emphasises temporal and spatial heterogeneities of socio-energetic relations. Our analysis focuses on how communities relate to a landscape in which certain energy practices are conceived and generated. How people understand and live with energy relates to practices of energy use and these practices emerge within a given bundle of meanings and materials, which cannot be reduced to the actual uses of energy or to the provision of an abstract resource (Shove and Walker, 2014). Rather, practices emerge in relation to a variety of the networks that provide energy, the characteristics of the built environment that predefine its use and the management and consumer cultures that define how energy is used. Such assemblages relate to spatial and temporal patterns of use that may be rationalised in community exchanges (Walker, 2014).

The phrase energy landscape evokes the physical environment that provides energy for human use (Stremke and van den Dobbelsteen, 2012). From this perspective, reading energy landscapes is akin to revealing the processes whereby natural landscapes are transformed into human landscapes (Pasqualetti, 2012). However, if we think about landscapes as emerging from the continuous interaction, the coevolution of societies and ecologies, as enshrined for example in the European Landscape Convention or in the UN World Heritage Convention, the notion of the energy landscape also opens up avenues to think about how energy is embedded in everyday life in communities. In studies of energy and communities, communities have been defined as social groups that are actively involved in the social construction of needs and uses of energy and that, sometimes, may also be involved in the provision of energy (Schweizer-Ries, 2011). Communities may thus refer to different forms of social organisation from the household to regional communities. In this paper, however, we focus on a very specific type of community within an urban setting, grouped in relation to a bounded area, their neighbourhood and sharing a system of governance, with a neighbourhood representative. Such a community is engaged in place making activities that constitute such places as 'activity spaces' (Massey, 1995) or as meeting points of multiple and fragmented interactions (Casey, 1998; Manzo, 2003).

A focus on community and energy landscapes helps understanding of both how people experience socio-energetic relationships and how they respond to them, for example, in relation to public reactions to wind energy projects (Pasqualetti, 2011) and how people cope with spatial transformations associated with the energy industry (Castán Broto et al., 2010; Parkhill, Butler and Pidgeon, 2013; Simmons and Walker, 
2005). However, energy landscapes are also shaped by daily interactions which may not be manifest in political debates about energy provision.

Alternatively, energy landscapes provide an entry point to understanding energy practices, from the point of view of how those practices are situated in a particular location and moment. The notion of energy landscapes focuses on the agency of those elements that are normally thought of as being in the background: the ecology of the place, the topography, the built environment characteristics, the political system, and cultural practices. Within a city we can think of energy as related to a socio-technical system composed of regimes of practices, flows of energy and technology and artefacts which, within a particular urban setting, enable function and use. The energy landscape emerges as the fabric that sustains energy artefacts, regimes and flows. How transmission towers are integrated in the local architecture; how people perceive the organisations that provide energy; how fuels such as charcoal move through a given city: these examples point at aspects of socio-energetic relations that need to be understood in relation to urban energy landscapes. Energy landscapes are thus connective tissue, a highly contextualised membrane that helps society to mould and be moulded in relation to an energy system. The socio-energetic relations that constitute everyday life in urban communities need to be understood together with the ongoing constitution of an energy landscape.

Following this, the focus of this paper is on how urban communities and urban energy landscapes are co-constructed through the daily tasks that shape the landscape and the way the landscape is understood and apprehended. The central question is how energy is embedded in the daily life of an urban community. We operate from the hypothesis that communities share an urban energy landscape that structures their daily routines, their energy needs and their expectations about why energy infrastructure matters for the long term sustainability of the community. In this vein, our research focuses on collective accounts of the spatial and temporal dimensions of energy use in a given neighbourhood that emerge from a community mapping exercise.

\section{Methodology}

Community mapping refers to a wide range of methodologies for mobilising communities and gathering information that can support action towards their development (WaterAid, 2005). Participatory mapping is a type of community mapping that emphasises the co-production of knowledge between researchers and research participants through the use of a combination of dialogue and the production of visual artefacts (Corbett, 2009). One of the strengths of participatory mapping is that through the engagement with different media, participants are able to share the multidimensional features of collective experiences of place: its perception, representation and how individual and collective histories link to it. In this way, participatory mapping needs to be conceived of as an encounter of different perspectives, in which both participants and researchers are learning together about shared experiences of place.

In practice, participatory mapping entails the production of a map that represents collective visions of a given community. A map is not necessarily a topographic representation of the place, but rather, it is a visual representation of socio-spatial relations which has capacity to influence them and hence, may be used as a political tool (Kitchin, Perkins and Dodge, 2011; Wood, 2012). Thus, participatory mapping is a strategy to empower communities through the composition of community-relevant maps. Participatory mapping of energy has mostly been confined to improving public participation in planning and decision making (Higgs et al., 2008) but, to our 
knowledge, there has not been an assessment of urban energy landscapes such as the one we propose in this research.

\section{The case study: situating Chamanculo $C$ in the context of urban development and energy in Maputo, Mozambique}

Maputo is the capital of Mozambique, a growing urban area whose history has been shaped by political turmoil and the reliance of the whole country on the city-port. The failure of the colonial government to actually govern the city, the Portuguese exodus in 1975 which included the dismembering of the systems for management of infrastructure in the city, the war from 1977 till 1990, and the cyclones that ravage the city sporadically are all factors that impact today's infrastructure landscape. Maputo is often thought of as 'two cities': one called 'the cement city,' the planned area with tarmac road and relatively reliable infrastructure services, and the informal settlements known as 'the reed city', named for the reed-build homes, standard in preindependence times. Although today reed-build homes are rare, 'the reed city' is still subserviced; it is clogged by its deficient transport links and plagued by problems in the water and sanitation services, waste management, and to a lesser extent, the provision of energy. Figure 1 shows this division between 'the cement city' (District 1) and the rest of the districts, specifically with regard to the areas with electricity connections.

Figure 1: Percent Households with Electricity in Maputo City, Mozambique

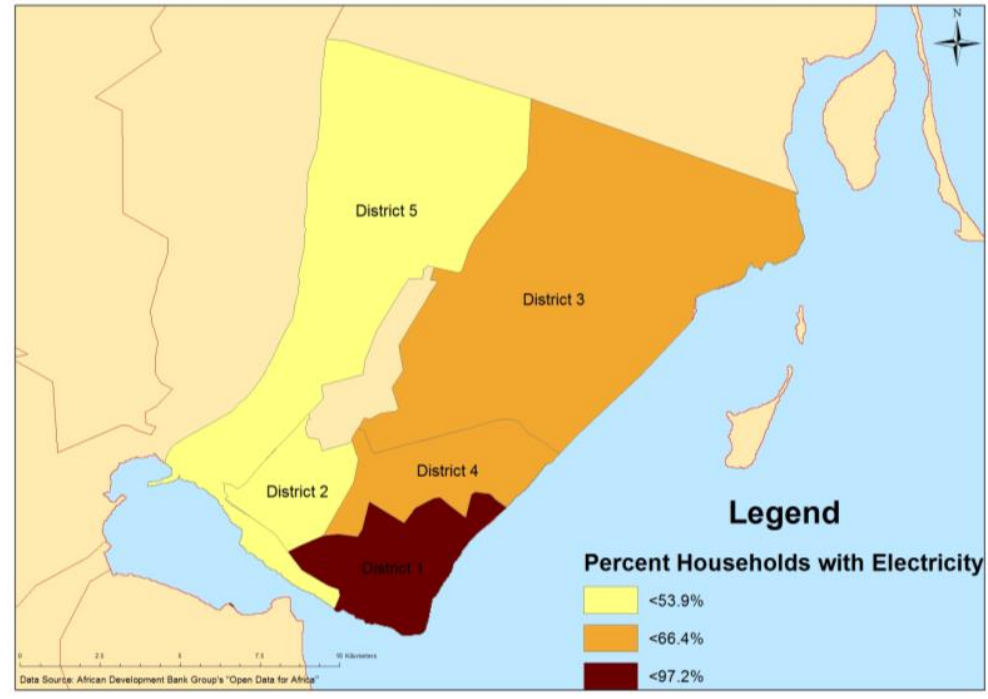

Thinking of the city as two cities, one formal and one informal, is inaccurate because both the formal and informal take part in the lives of all five districts. In districts that are described as 'the reed city' there is a very rigid system of neighbourhood governance, which relates to the political structure of the ruling party FRELIMO (Front for the Liberation of Mozambique). The city is thus divided into bairros, quarteirões (a subdivision of fifty to one hundred houses) and groups of ten houses. The bairros have a secretary. The quarteirões and groups of ten houses are administrated by Chefes of quarteirões and Chefes of dez casas, respectively in which Chefes have a historical role as informants to and of the local population (Boyd et al., 2014). 
Chamanculo $C$ is a historical bairro divided in 97 quarteirões. The bairro is on the boundary of the cement city and thus, it benefits from easy access to the city in terms of both providing employment and trade opportunities. The bairro suffers from deficiencies in infrastructure, especially water and sanitation and waste management. Waste management is particularly important, because the deficient drainage and uncontrolled dumping of waste are key factors that increase the vulnerability of the neighbourhood to flooding, as was the case with recent cyclones, such as Cyclone Funso in 2012 (for a review see: Castán Broto, Oballa and Junior, 2013).

In local government accounts, supported by local academics, access to energy is conceptualised in terms of access to the energy network both in terms of physical access to that network and in terms of affordability. With regards to energy infrastructure, the electricity coverage of the city has improved considerably in the last several years. Local officials are keen to highlight the success of a pre-paid system of energy provision, which enables divisibility of energy and thus, makes energy affordable because people can buy small quantities of it (Baptista, 2014). However, an exclusive focus on access to the energy network overlooks the diverse ways in which energy is embedded in everyday life and sustains diverse livelihoods. To contextualise this research, we conducted a survey of energy poverty in 40 households in Chamanculo $\mathrm{C}$, following the methodology of Practical Action's Total Energy Access survey (Practical Action, 2012) and inquiring into basic services for lighting, cooking and water heating, space heating and cooling, and communications. Our survey showed that all but one household had access to electricity. Only 70 per cent of the households met the minimum standard for lighting services, but this was not related to a question of access to the electricity network but rather, to its affordability. Yet the service with the highest percentage not meeting the minimum standard was cooking and water heating (only 65 per cent met the minimum standards in terms of access to fuels and pollution levels). As the survey showed, the majority of households rely on charcoal for cooking and heating water. On the other hand, the survey also showed that the majority of people had access to communication appliances and it pointed towards the rapid spread of communication technologies such as mobile phones. Overall, the survey suggested that socio-energetic relationships in Chamanculo $\mathrm{C}$ were complex and could not be reduced to a question about infrastructure access and affordability.

\section{The participatory mapping workshop}

Participatory mapping is a methodology suited to understanding socio-energetic relations both in respect to different understandings of energy within the community and how they relate to other aspects of life in their neighbourhood. Chamanculo $C$ is a historical bairro in Maputo whose members are active in constructing the neighbourhood. We have worked in Chamanculo C since 2011 and thus, we have established relationships with community members and local organisations. We developed this research project in partnership with Foundazione AVSI, an NGO that has recently completed participatory spatial planning in this area for the Maputo Municipality. Previous participatory research on development priorities in the area (Castán Broto et al., forthcoming) showed that while residents were actively concerned about services in their area, access to energy was not a generalised concern. Yet, energy services are of great importance in the bairro, because of their relationship with security concerns, their impact on income, and the recent institutional changes related to the implementation of a pre-paid system which seems to have improved residents' access to electricity (Baptista, 2014).

The participatory mapping workshop took place in a collective facility in Chamanculo C in July 2014. We recruited 25 participants from the whole bairro, selected through the institutional structure to represent diverse quarteirões. 
Participants were also from a broad range of ages (from 18 to >80) and both men and women were represented; the bairro Secretary and three Chefes also attended. The workshop took the whole day and ended with a collective party as a means to acknowledge everybody's participation and time. The workshop had three parts: in the first activity, participants were given time to look through photographs of the different elements of the energy system. When they found one with particular significance, they were invited to discuss it with the group, naming the object and explaining where it comes from and where it goes. Participants found it difficult to engage with this activity, perhaps because it was at the beginning of the workshop, but it helped to focus the conversation around energy services and prompt thinking about diverse energy relationships in their community. The second activity was a group discussion in which we asked participants to discuss different energy services (lighting, cooking, space, and communications) in relation to the temporal patterns of energy use through the day and throughout the year. There were four panels, one for each service, and participants rotated groups. Each group drew a conceptual diagram of issues discussed that was presented back to all participants in a wrap-up session. The final section of the workshop focused on the spatial experiences of energy systems in the neighbourhood, bringing participants to take part in a walkshop (Leach, 2014), e.g. using a walk to foster conversations about the energy landscape. Participants proposed the routes for the walkshop and two groups led the walk in the neighbourhood, mapping different objects relevant to understanding the energy landscape on a base map of the area (Figure 2).

\section{Figure 2: Workshop participants drawing a map of the walkshop}

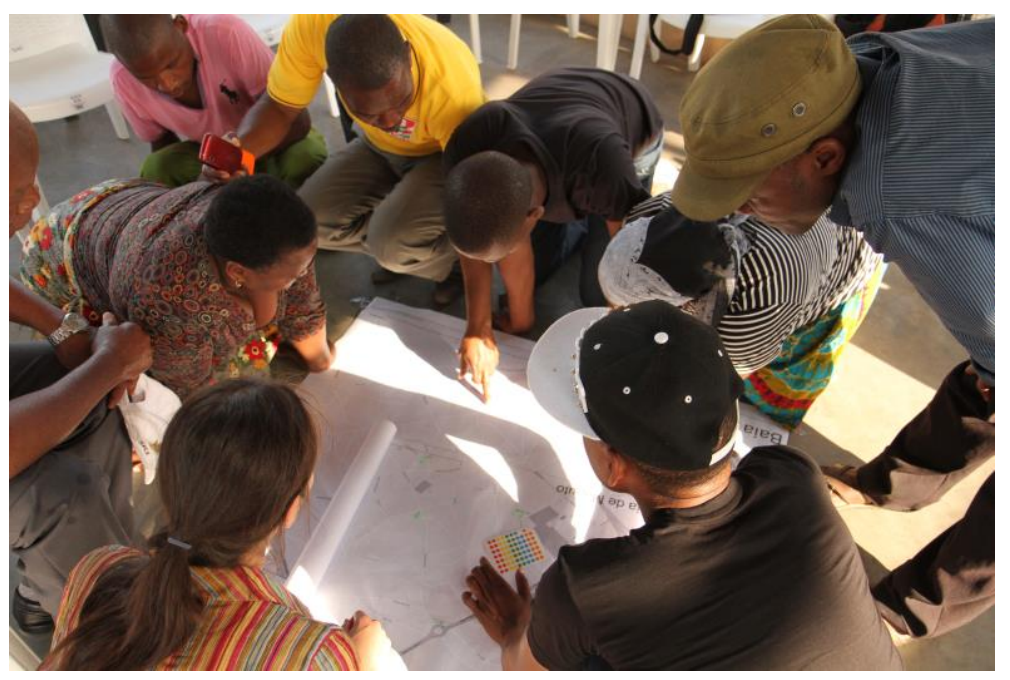

The different structure of the activities allowed participants to mix themselves in terms of age group and gender. Also the use of different elements such as photos, maps and various resources during the group discussion facilitated a wider contribution; nevertheless, it was noticeable that young people, the Chefes of quarteirões and a female participant who was a teacher had active participation while elderly people remained quieter. We recorded both voice and images of all the group presentations and discussions that were later transcribed for analysis. We also used direct observation and our diaries to capture impressions and information. The materials assembled were analysed to examine 1) how energy is relevant in people's lives and 2) how it is understood in relation to different expectations about energy needs and uses of energy. 


\section{Energy landscapes in Chamanculo C}

The initial exercise with photographs suggested that participants were quite familiar with the diverse mechanisms for the production and distribution of energy (whether this was electricity, charcoal or other mechanisms) but had difficulty in identifying energy appliances and their relation to energy services, perhaps because small variations in appearance made the artefacts difficult to recognise. For example, pictures of cookstoves relatively similar to those in Chamanculo were not immediately recognised. There were also discussions about what actually constitutes a part of the energy system, for example, whether or not a candle was a part of it, and whether candles were used at all in the neighbourhood.

Community members showed with pride a photo of the Cahora Bassa dam, one of the largest hydropower facilities in Africa but which is part of a wheeling arrangement between Electricidade de Moçambique (EDM) and the South African energy company Eskom, whereby Cahora Bassa provides energy to Johannesburg and Eskom provides cheaper electricity to the south of Mozambique. Participants spoke of Cahora Bassa as something they would like to learn about, and attached great significance to it as the dam is an important symbol of the modernisation of the country.

The exercise also highlighted the importance of charcoal in the local economy and residents described in detail the flows of charcoal from distant regions where it is produced (Matutuine, Xikwala Kwala) and the way it is distributed within the community, with the provision centralised in large markets of charcoal and low scale distributors that sell small amounts of charcoal in local markets and neighbourhoods. Participants spoke of charcoal both in relation to its insertion in the local economy and the way it links them to the spaces where charcoal is produced.

Figure 3 presents the results of the collective effort by participants to describe the energy landscape in Chamanculo $C$. The diagram is a composite of digital representations of four working groups in which participants discussed lighting, cooking and heating water, cooling and heating space, and communications. This diagram is intended to present part of the data produced in the workshop, rather than as an analytic representation of the discussions by the authors of this article. We have added to the original diagrams two notes in the corners that indicate whether the discussion focused more on the spatial elements in relation to energy or the artefacts that were involved in their use. 


\section{Figure 3: Diagram of different elements of the energy landscape in Chamanculo C}

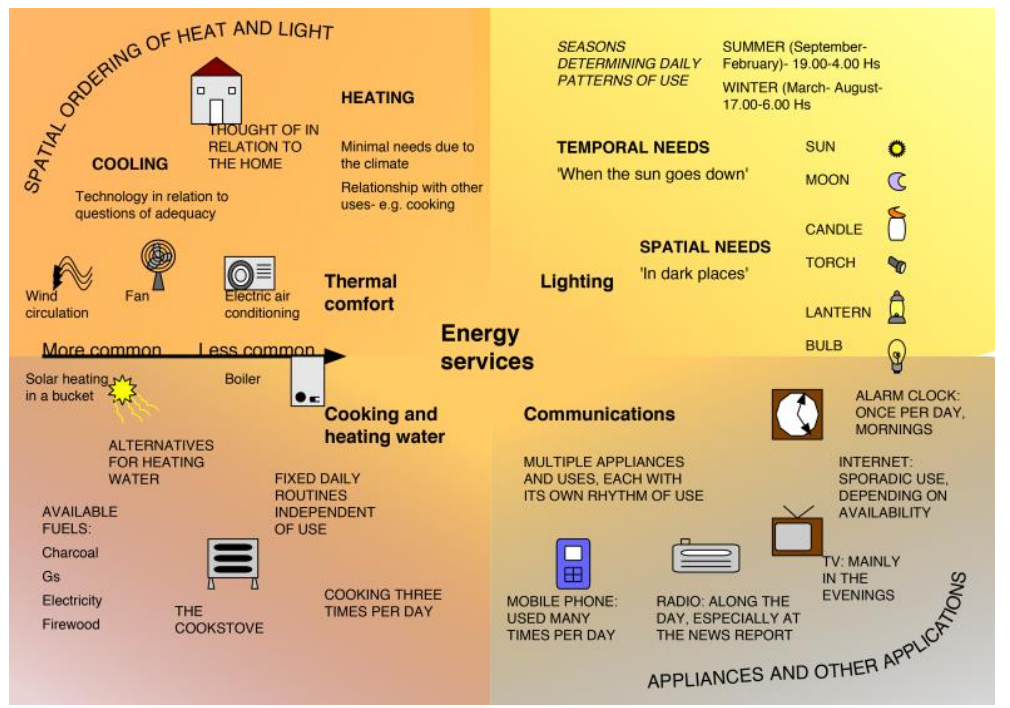

The key feature of energy that was found to most closely relate to the spatial aspects of the neighbourhood was thermal comfort and food preservation. Here, the house was presented as the unit to describe different practices of heating and cooling space. Heating was not thought of as an issue of great concern because of the relatively benign climate in Maputo which, according to participants, is never too cold. Cooling needs awakened more debate. Although most participants argued that they simply opened the window when it was too hot, participants had a vibrant debate about the use of fans and air conditioning units. Part of the discussion was around the temporalities of using air conditioning or electric heaters. For example, when a person argued that the electric heater was only used in the night many participants were agitated. One of them stated:

"Suppose the day dawned cold, would then a person not turn on the electric heater? It would turn it on only in order to be inside the house; it is not only in the night, [whether it is used or not] depends on the temperature inside the house."

A forceful discussion ensued which is not audible in the recordings, but of which we took notes. Participants discussed at length the 'correct' use of electrical appliances to maintain thermal comfort. Eventually, the facilitator asked each participant to explain how they were using it themselves, in their own houses. The audience responded with laughs, and then one of them stated to general agreement that they did not have such appliances and that this was the reason why they did not know how to use them. At this moment, the whole group presented themselves as a community that maintains a collective strategy of engagement with thermal comfort appliances, distinct from those who use them daily and know how to use them (as represented, for example, by the facilitators). They drew this on the conceptual map, in terms of the extent to which certain ventilating technologies were more or less common.

There was some agreement around the significance of lighting in community life. For example, the group was in agreement that the extension and upgrading of public lighting in the last few years had benefited the community directly, through the improvement of the safety conditions in shared spaces. 
"Public lighting contributes mostly to our security. We are safer because the streets without lights after dark are a problem, because of many reasons from random encounters with criminals to stumbling upon a stone; with public lighting we can see and then we walk."

Safety is a collective good in the community. In Chamanculo $C$, the few main roads are connected by narrow and unpaved paths which are unsafe without proper lighting. Public lighting, though, is confined to the main roads and hence, participants noted the importance of alternative means of lighting along these paths, including the moon as a source of lighting (Figure 3). In this way, lighting is related to spatial aspects: the distribution of the houses in the neighbourhood, the presence of appropriate roads, and people's ability to bridge distances through walking.

Lighting also relates to the electrification of the household. Here is where lighting becomes more closely related to yearly patterns of energy use, and the way the length of the day bears influence in electricity consumption. Participants noted a considerable seasonal difference, with a higher energy bill in the winter, when days are shorter. The categorical depiction of seasonal differences highlights the way the implementation of a pre-paid system for the provision of electricity, and the fact that lighting is the main service obtained from electricity, enable local residents to understand and control their own demand of light, to the point that they share a common view about consuming more electricity during winter. The pre-paid system has also changed perceptions that illegal connections were encroaching in the collective infrastructure and residents argue that illegal connections to the electricity network have almost disappeared in the neighbourhood. This perception matches the cartographic evidence gathered by AVSI for a participatory local plan in 2012 (AVSI, 2012).

Procedures of cooking and water heating also raised discussions. Residents agreed about charcoal being the main fuel for cooking. They explained that people may use other fuels for different reasons, depending on whether they can afford them, or linking those fuels with particular occasions and uses (such as the use of firewood in parties). The discussions, however, focused on when energy for cooking was needed, in relation to different life patterns. This points towards a process of spatial ordering around the stove, rather than around the house. Participants emphasised that there were fixed routines of cooking and heating water, which followed the number of meals per day. They explained that they eat three times per day, always at set times. There is coordination between large meals and heating water for which they may use a range of technologies from an electric heater to solar water heaters. A male participant explained:

"Most of all, in the morning we use firewood, or charcoal or electricity to heat water for breakfast; then, by mid-day, the ladies take the pots and prepare the food for lunch; in the afternoon they again may take the pots, I do not know, around 5 or 6 in the afternoon, to cook for dinner and after dinner we still have to heat water to bathe our children, our father, our mother. So we drew [in the map] these three times in which we cook, but there may be more, but these are the three moments that we all share and this is what we drew here."

A collective rhythm of cooking also brings the community together both in terms of what they do but also who they are, and how they relate to the task at hand, for example, women are thought of as being responsible for preparing food (Figure 4). Cooking is also related to spatial ordering. For example, that fact that improved cookstoves allow for cooking inside the house has been one of the main factors for the success of a cookstove improvement programme led by AVSI. 
Figure 4: A woman cooks using an improved cookstove

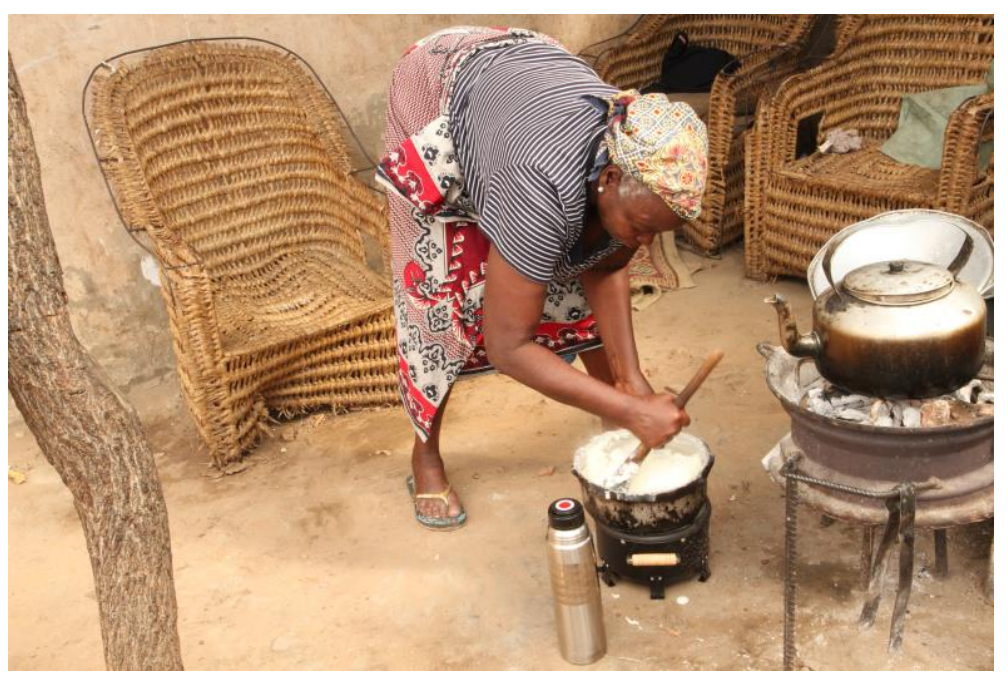

Communications were treated entirely differently from other uses in two ways: first, different rhythms and forms of energy use were discussed in relation to the actual 'demands' of the appliances and the way they were integrated into people's everyday lives; second, thinking of energy as a means for communication prompted questions about what energy actually is and its significance in their own lives.

With regards to communication, appliances impose their rhythm on the life practices in Chamanculo C. Some participants highlighted the alarm clock, the appliance that marks the start of the day. The mobile phone, as generally agreed, was used thorough the day. The radio was very significant too, particularly because, as participants explained, it had historically brought communities together at the times of the news, although there was some speculation about whether this continues to be as important as it was in the past, with the prevalence of television and the internet increasing. With regards to the television one participant explained that:

"The use has increased because the more we know it, the more we use it every day. We have children and we watch it almost every night, to watch the soap and we do that with the whole family. Most households watch TV at night."

Part of the story requires the representation and portrayal of households as closeknit families, and, as in the arguments explained above around cooking and heating water, considering collective life as a factor structuring energy use. This is also facilitated by the spatial distribution of households, in which separated rooms are most often arranged around a courtyard, which is shared with members of the extended family or neighbours. Participants also talked about their use of internet, particularly in internet cafes, and the fact that patterns of internet use were closely linked to individual preferences. So, while participants established social patterns in relation to the use of TVs and radios, or the practices of cooking and lighting, they situated technologies such as internet and mobile phones as individual-based technologies, for which social patterns could not be identified.

The theme of communications not only raised questions about the variety of rhythms in energy use and whether different appliances were embedded in everyday life or not, but also, it fostered a vivid discussion about what was energy and what was not energy, particularly in relation to the observation that, according to participants, 
communication relied on people themselves talking or writing to each other. This was followed by a discussion about the extent to which human energy, food and other actions were also part of the energy system. Such views reveal how when departing from the perspective of experience, energy questions raise issues which are not necessarily subsumed in a merely utilitarian understanding of what energy is and why it matters.

The final section of the workshop linked space, energy and views of the neighbourhood through two walks across Chamanculo $C$ to observe and interact with different elements that they considered part of the energy system; the walks were followed by the collective mapping of the features observed and a discussion. Both walks were significant not just because of what participants highlighted but also because of what they ignored. As they were instructed to think about community and energy they avoided households (although they showed them when prompted) focusing instead on collective artefacts. When thinking about energy uses and their dynamics, participants in the workshop emphasised the home as the central unit for energy consumption, either implicitly or explicitly, and related the energy system to the home and home-based artefacts. However, when they were walking around the neighbourhood participants highlighted their awareness of infrastructure in shared spaces and how it becomes visible in their everyday lives.

For example, participants pointed at public lighting, transmission towers, and electricity connecting points. In both walks participants highlighted every electricity transmission station in the neighbourhood as part of the collective energy infrastructure. This is infrastructure that bears little relevance to their everyday life in any other way than as an object that facilitates energy connections and as a source of concern when there is an electricity fault. The idea that energy infrastructure is invisible to people as they go about their daily life is pervasive in energy research, but our research shows that citizens are well aware of the location of every transmission station in their neighbourhood.

In relation to the markets of energy, residents mapped key institutional dependences such as the nearest office of the energy company Electricidade de Moçambique and the markets of gas and charcoal. The linkages between charcoal and livelihoods were continuously emphasised, with stories about residents getting rich because "they sold a lot of charcoal and bought a big house." What was rarely emphasised, however, even when prompted, were the shops to buy credit for electricity within the pre-paid system (Credelec). This is now bought in local shops alongside other goods and it is perceived as separate from the overall energy system, as if the capital flows were separated from those of electricity and the energy uses that they facilitate. 
Figure 5: Infrastructure is embedded in the construction of the houses

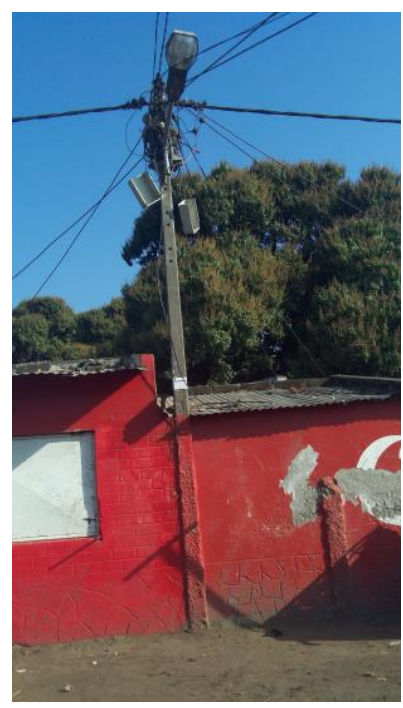

Like household artefacts, such infrastructure artefacts are also embedded in complex social and institutional relationships. The walk, for example, constituted an opportunity to talk about issues with individuals which were not raised in the collective discussion. One resident explained his concerns about people who lived in some houses temporarily, as 'tenants' may have different energy habits, for example, using more plastic and waste as fuel. The walk also showed how infrastructure is embedded in physical relations, for example, being integrated in the actual construction of houses (see Figure 5). Overall, the analysis above points towards the complex social, spatial and material relations that structure the different uses of energy in Chamanculo $\mathrm{C}$ and contributes to an energy landscape which reflects community rhythms and artefacts.

\section{Conclusion}

Focusing on energy landscapes allows for an examination of the socio-energetic relationships which emerge within a specific urban context. In Chamanculo C, the participatory mapping workshop provided evidence of residents' perceptions of energy services and how they act upon them. This in turn reveals important aspects of a shared community life and how it unfolds in the place in which they live. For example, the exercise revealed the social patterns of energy use, with women responsible for cooking with fuels such as charcoal, and the way mobile communication appliances were perceived as objects for individual role, in contrast with the radio which had played in the past an enormous role in organising community life.

Complex socio-energetic relationships are visible in the urban energy landscape. The most salient feature is the collective expression of the contrast between the expected and the experienced. Local residents' accounts demonstrate that there is a perceived difference between how energy artefacts should be used and how they are used within the particular historical and spatial context in which they situate themselves. This relates to a process of urban differentiation in which residents in Chamanculo $C$ explain differences between areas in the city where charcoal is widely used or not; or areas in the city where they have access to modern facilities or different needs such as extra heating and cooling in a relatively benign climate. 
The analysis also shows the potential of focusing on energy landscapes as the connective tissue that supports flows, artefacts and regimes, for understanding local energy cultures. The case provides different examples of how regimes of energy use are configured not just in relation to any preconceived ideas about how energy should be used, but rather, in relation to existing socio-spatial patterns of living and the artefacts that symbolise them: in particular, the house and the cookstove. Charcoal and stoves are inserted into daily routines that do not simply disappear with access to electricity. Forms of institutional innovation succeed because of their close fit with the existing energy landscape. The flows of energy resources through the neighbourhood are also known to participants even when they do not fully understand the operation of the technologies involved. The flow of materials through the neighbourhood makes local residents acutely aware of what is possible, and the way things flow in, out and through their neighbourhood. For example, flows of charcoal organise the local economy and the relations of Chamanculo $C$ with the wider city and other locales. Access to electricity structures ideas of local progress and hence, local residents have a heightened awareness of the landscape artefacts that facilitate such connections from transmission towers to the local office of the energy company.

The materiality of artefacts does not only relate to the objects that are actually used by residents in their daily lives, but also to other elements of the energy landscape which are visible, even if local residents do not take part in their management and regulation. Community residents engage with landscape artefacts even when they are not inserted in their daily routines of energy use. Even when they do not know exactly what such components do or why they matter in energy provision, they constitute artefacts of great significance in their neighbourhood, contributing to build up a sense of shared ownership and of neighbourhood improvement.

The participatory mapping of energy landscapes in Maputo was also an exercise to develop a pilot methodology and demonstrate its potential for understanding energy landscapes. Participatory mapping provided insights into a multiplicity of views on how energy matters in Chamanculo C. Moreover, the focus on energy and community mapping enriches previous participatory urban planning processes in Chamanculo C. This is a methodology whose relevance could also be explored in other contexts, for example, to understand socio-energetic relations in UK communities.

\section{Acknowledgements}

This research was funded with a Future Research Leaders Grant from the Economic and Social Research Council (grant reference: ES/K001361/1). We wish to thank the support from AVSI, specially Felisbela Materula. We also wish to thank the support of the people of Chamanculo C.

* Correspondence address: Vanesa Castán Broto, Bartlett Development Planning Unit, 34 Tavistock Square, London. Email: v.castanbroto@ucl.ac.uk 
p. 206. Communities and urban energy landscapes in Maputo, Mozambique

\section{References}

AVSI (2012) Diagnostico Socioéconomico da Comunidade de Chamanculo C. Maputo: AVSI.

Baptista, I. (2014) Everyday Practices of Prepaid Electricity in Maputo, Mozambique. Oxford: University of Oxford.

Boyd, E., Ensor, E., Castán Broto, V. and Juhola, S. (2014) Environmentalities of urban climate governance in Maputo, Mozambique. Global Environmental Change, 26, 140-51.

Casey, E.S. (1998) The Fate of Place: A Philosophical History. Berkeley/LA/London: University of California Press.

Castán Broto, V., Burningham, K., Carter, C. and Elghali, L. (2010) Stigma and Attachment: Performance of Identity in an Environmentally Degraded Place. Society \& Natural Resources, 23, 10, 952-68.

Castán Broto, V., Oballa, B. and Junior, P. (2013) Governing climate change for a just city: challenges and lessons from Maputo, Mozambique. Local Environment, 18, 6, 678-704.

Corbett, J. (2009) Good Practice in Participatory Mapping. IFAD.

Cowell, R., Bristow, G. and Munday, M. (2011) Acceptance, acceptability and environmental justice: the role of community benefits in wind energy development. Journal of Environmental Planning and Management, 54, 4, 53957.

Grubler, A., Bai, X., Buettner, T., Dhakal, S., Fisk, D.J., Ichinose, T., Keirstead, J., Sammer, G., Satterthwaite, D. and Schulz, N. (2012) Urban energy systems, In: L. Gomez-Echeverri, TB Johansson, N. Nakicenovic, and A. Patwardhan (Eds) Global energy assessment: Toward a sustainable future. Laxenburg, Austria: International Institute for Applied Systems Analysis.

Higgs, G., Berry, R., Kidner, D. and Langford, M. (2008) Using IT approaches to promote public participation in renewable energy planning: Prospects and challenges. Land Use Policy, 25, 4, 596-607.

Kitchin, R., Perkins, C. and Dodge, M. (2011) Thinking about maps, In: Dodge, M., R. Kitchin, and C. Perkins (eds), Rethinking maps: New frontiers in cartographic theory. London: Routledge.

Leach, M. (2014) The Wonders of Walkshops. Brighton: STEPS Centre Blog.

Manzo, L.C. (2003) Beyond house and haven: toward a revisioning of emotional relationships with places. Journal of Environmental Psychology, 23, 1, 47-61.

Massey, D. (1995) The conceptualization of place, In: D Massey and P. Jess. (eds), A Place in the World? Milton Keynes: The Open University Press, pg. 45-86.

Parkhill, K.A., Butler, C. and Pidgeon, N.F. (2013) Landscapes of Threat? Exploring Discourses of Stigma around Large Energy Developments. Landscape Research, 1-17.

Pasqualetti, M.J. (2011) Opposing wind energy landscapes: a search for common cause. Annals of the Association of American Geographers, 101, 4, 907-17.

Pasqualetti, M.J. (2012) Reading the Changing Energy Landscape, In: Stremke, S., and A. van den Dobbelsteen (eds), Sustainable Energy Landscapes: Designing, Planning, and Development. Boca Raton: CRC Press: pp. 11-44.

Practical Action (2012) Poor people's energy outlook 2012: Energy for earning a living. Rugby: Practical Action Publishing.

Schweizer-Ries, P. (2011) Socio-environment research on energy sustainable communities: participation experiences of two decades. Renewable Energy and the Public: From NIMBY to Participation: 187-202.

Seyfang, G., Haxeltine, A., Hargreaves, T. and Longhurst, N. (2010) Energy and Communities in Transition: Towards a new research agenda on agency and civil 
p. 207. Communities and urban energy landscapes in Maputo, Mozambique

society in sustainability transitions. CSERGE working paper EDM. University of East Anglia.

Shove, E. and Walker, G. (2014) What Is Energy For? Social Practice and Energy Demand. Theory, Culture \& Society, 31, 5, 41-58.

Simmons, P. and Walker, G. (2005) Living with technological risk: industrial encroachment on sense of place, In: Å Boholm and R E Löfstedt. (eds), Facility sitting: risk, power and identity in land use planning, London, Sterling, VA: Earthscan.

Stremke, S. and van den Dobbelsteen, A. (eds) (2012) Sustainable energy landscapes: designing, planning, and development. Boca Raton: CRC Press.

Walker, G. (2014) The dynamics of energy demand: change, rhythm and synchronicity. Energy Research \& Social Science, 1, 49-55.

WaterAid (2005) Community Mapping: A tool for Community Organising. London: WaterAid.

Wood, D. (2012) Rethinking the power of maps. Guidlford: Guilford Press. 